This is an Accepted Manuscript of an article published by Taylor \& Francis in Social Work Education on 27/10/16, available online:

http://www.tandfonline.com/doi/full/10.1080/02615479.2016.1249836 


\title{
On the learning journey: what helps and hinders the development of social work students' core pre-placement skills?
}

\author{
Author Names: Hilary Tompsett, Kathleen Henderson, Jane Mathew \\ Byrne, Elaine Gaskell Mew and Chris Tompsett
}

Kingston University/St George's University of London, London, UK

\section{Correspondence details:}

Research team: Professor Hilary Tompsett h.tompsett@sgul.kingston.ac.uk

Course Team: Kathleen Henderson: k.henderson@sgul.kingston.ac.uk

\begin{abstract}
The development and assessment of core skills, including communication skills, are essential pre-requisites before social work students are judged ready for practice placement. This paper presents qualitative data from the first year of a three-year study of an undergraduate module taught jointly to undergraduate and postgraduate students on two qualifying programmes at a university in England. The study considers the impact of video recording in a 'skills laboratory' on social work students' skills development, and compares this with other feedback mechanisms at the pre-placement 'Readiness for Direct Practice' threshold for the different student groups. Responses from 88 students to two questions on factors they identified as the most helpful/least useful for core skills development were collected, using the same questionnaire at three stages of the module. These were analysed using a grounded theory approach. A separate, quantitative analysis showed that assessment outcomes for undergraduate and postgraduate students were not statistically different. In contrast, this qualitative analysis showed that while there was common value for students from self-observation using video, there were key differences in learning preferences between undergraduates and postgraduates in relation to feedback. While undergraduates valued peer support in groupwork, postgraduates preferred feedback from authoritative, independent and credible sources.
\end{abstract}

Keywords: communication skills; self-observation; readiness for direct practice; higher education; skills laboratories; video; feedback. 


\section{Introduction}

Social workers, once qualified, need to be able to exercise professional judgement, informed by theory, research and values, in situations of uncertainty and risk (Munro, 2011). First, however, as students, they must master core skills, so that "skilled behaviour (becomes) so routinized through practice and experience that it is performed almost automatically", allowing them to move on to the "deliberative processes" necessary for dealing with complexity (Eraut, 1994, p. 111-112).

Since 2013, social work students on qualifying programmes in England have to be assessed, more formally than previously, as 'Ready for Direct social work Practice' before first placement (the RDP threshold) and undertake 30 days of skills development before and alongside placements. By this threshold, students should demonstrate "basic communication skills, ability to engage with users, capacity to work as a member of an organisation, willingness to learn from feedback and supervision, and ... basic (social work) values, knowledge and skills" (defined by The College of Social Work (TCSW), 2012b). Communication skills are key at this level for developing interviewing techniques, but initial education must also develop related core skills, including critical self-reflection, intellectual and emotional intelligence, and self-awareness, as part of establishing professional confidence and identity (Fook and Gardner, 2007; Bruce, 2013; Croisdale-Appleby, 2014).

While skills development has always been a major component of social work education, the importance of the RDP (Readiness for Direct Practice) threshold at early stages has raised expectations even higher for educators engaged in this. Practice relevance, objectivity in assessment, innovative learning/assessment methods and a holistic approach are all expected (Trevithick, Richards, Ruch and Moss, 2004; Bogo et al., 2006; Moss et al., 2007; Keville, 2012). Research in this area is also much 
demanded (Trevithick et al., 2004; Bolger, 2014), but recognized as difficult to undertake (e.g., Koprowska, 2010) and rarely followed up into practice ( $c f$. Collins and Bogo, 1986).

This paper presents first year qualitative findings from a three-year study of an English university undergraduate module preparing undergraduate and postgraduate students jointly in core pre-placement skills. The overall study investigates the relationship between students' self-assessment of their skills and end of module outcomes. A separate paper (Tompsett, Henderson, Mathew Byrne, Gaskell Mew and Tompsett, 2016, in review) presents the study's first year quantitative data, a detailed overview of the methodological approach and the establishment of a self-efficacy scale, which had convergent validity with the mark gained for assessed interviews; the association was markedly stronger for undergraduates than postgraduates, although pass-rates and assessment outcomes were independent of programme level and previous work experience. This paper focuses on factors these students identified as most helpful/least useful for their skill development, and considers the impact of a practice learning suite/skills laboratory and students' programme level.

\section{Literature Context}

Nature, acquisition and transfer of skills

Despite conflicting views on potentially separate professional pathways for adult and children's social work, two government-commissioned reviews of social work education (Croisdale-Appleby, 2014; Narey, 2014) and differentiated 'Knowledge and Skills Statements' generated by two Chief Social Workers all agree and emphasize the importance of clear and sensitive communication skills as part of purposeful, effective relationships with adults, children, families and other professionals (DfE, 2014a; DH, 
2014). Communication skills are also seen as underpinning skills in negotiating, mediating, and advocacy (Trevithick, 2012), supervision (Dinham, 2006), crossdisciplinary assessments, decisions and care (Croisdale-Appleby, 2014), and higher level communication skills, that may be needed if encountering resistance and anger from parents/adults and families in practice (Forrester, McCambridge, Waissbein and Rollnick, 2008).

Lefevre, Tanner and Luckock (2008), (building on Luckock et al., 2006) defined communication skills as more than a set of techniques to be deployed, and, while focusing on communication with children, emphasized that this needs to be understood within a 'tripartite framework', integrating knowledge, values and personal capacity, and technical skills ('knowing', 'being' and 'doing'). Forrester et al., (2008) also noted that levels of knowledge, understanding, compassion and sensitivity are needed to appreciate hostile service user responses may be rooted in shame, ambivalence or low confidence.

Dinham's (2006) review of the practice and learning of communication skills in social work education in England research highlighted that respondents at that time had varying views on what was meant by "core", "specific" and "technical" skills, though "there was some consensus that 'core' skills are those which support direct interpersonal work and personal development, namely 'listening', 'self-awareness', 'empathy', 'choosing appropriate forms of communication for users' needs', 'questioning', 'non-verbal communication', and 'awareness of diversity and difference'.(p 844). While primary emphasis on the acquisition of basic communication skills remains, core skills at RDP level also include a range of other skills, (alongside relevant knowledge, values and communication/interviewing techniques), such as intellectual and emotional intelligence (Sheppard and Charles, 2014, 2015) to assist 
sensitive relationship-building (Ruch, Turney and Ward, 2010), and critical self-aware reflection to promote students' professional development (Fook and Gardner, 2007) and emerging confidence in practice and professional behaviour (Munro, 2011; Keville, 2012).

Few studies compare undergraduates' and postgraduates' acquisition of skills, despite government drivers for preferential funding for postgraduate routes to professional qualification (DfE, 2014b, 2016). Sheppard and Charles's two-site study $(2014,2015)$ of undergraduates and postgraduates focused on entry to social work training skills in "interpersonal dispositions" (emotional intelligence) compared with critical thinking skills (intellectual intelligence). They reported higher levels of critical thinking skills for postgraduates, but no differences in emotional intelligence. Whether education/training enabled transfer to practice or which aspects of learning have greater influence on undergraduates/postgraduates is, as yet, unreported. Parker's (2006) study with a self-selected sample of 23 undergraduate and postgraduate students in placement reported differences in confidence and perceptions, but across sets of students, not differentiated by programme level. The multi-method evaluation of 'Frontline', an employer-led postgraduate fast-track programme (Maxwell et al., 2016), tested the 'practice quality' of 49 self-selected trainees' interviewing skills in an interview with a simulated 'service user' and a brief written reflection, but did not test this before training started. Direct comparisons with an unmatched sample of undergraduate/postgraduate students on 'mainstream' programmes suggested the comparison group students, at both levels, scored lower for interviewing and written reflection skills, but higher in relation to confidence levels.

Transfer of skills to practice contexts is widely seen as problematic. Collins and Bogo (1986) tested students' interviewing skills in university and in early placement. 
While they noted improvement in skills after simulated practice with peers, they found that quality of interviewing decreased in placement on all of their three holistic measures (empathy, warmth, and genuineness). In Parker's (2006) study, students reported, in terms of skills in which they had confidence, that their communication/interviewing skills had improved during placement; they felt, however, insufficiently prepared in emotional resilience for coping with violent service user responses. It is argued that developing skills in self-awareness, reflection and selfevaluation can enable students/practitioners to re-appraise their competence, take advantage of supervision, and develop appropriate confidence and authority (Munro, 2011), enabling the transition from competent practice to 'critical practice' (Adams, Dominelli and Payne, 2002).

\section{Learning, Teaching and Assessment of Skills}

Programmes of core skills development focus primarily in early stages of training on communication and interviewing skills, while acknowledging other related knowledge, skills and values, (Trevithick, 2012), and assessment of social work students as "ready for direct practice" before undertaking first practice placements includes microskills, as well as broader skills. Microskills, breaking down communication skills into effective building blocks (as used in counselling, e.g., Ivey, 1982) remains a key starting point for professional learners. Ivey's hierarchy of microskills for "intentional interviewing" identified basic attending and listening skills (including reflection of feeling and meaning), before separating out skills for focusing, influencing, confrontation, sequencing and structuring interviews, alongside integration skills, applying previous skills in new ways and matching with different theories/models, situations and cultural groups. 
While many professions teach and assess communication skills (e.g., Laidlaw and Hart, 2011), social workers rely mainly on interpersonal and communication skills to make sense of difficult behaviours and situations in diverse contexts and communities without the underpinning of more objective procedures (CroisdaleAppleby, 2014, p 15). The development of social work skills has to be contextualized within professional principles/values and a recognition of the emotional demands of practice (TCSW, 2012b; Munro, 2011). Effective teaching and assessment of social work students' communication and culturally sensitive skills is therefore essential but also complex.

Differences in professional regulation and frameworks influence models of learning and assessment. The Professional Capabilities Framework (PCF) in England (TCSW, 2012a), developed by the sector-wide Social Work Reform Board (2010), supports an integrated holistic approach to foster professional discretion, judgement and creativity alongside competence ( $c f$. Eadie and Lymbery, 2007, reflecting Eraut). Ensuring regulatory and assessment consistency is challenging (Croisdale-Appleby, 2014; Narey, 2014), given the differently framed professional standards defined by the PCF, Health and Care Professions Council (2012) and the separate Knowledge and Skills Statements (see Moriarty, Baginsky and Manthorpe, 2015).

A measurable competency-based approach, as applied, for example, in North America (CSWE, 2015) facilitates clarity of learning goals and consistency in assessment approaches (Bogo et al., 2006) but can be seen as over-focusing on technical skill acquisition. This can be reduced by having a range of assessment methods (Crisp and Lister, 2002), enabling demonstration of microskills, broader skills and values, and student achievement, even with different learning strengths/styles. At the point of assessment for professional qualification, Bogo et al. (2013) advocate the 
use of OSCEs (Objective Structured Clinical Examinations, as in nursing/medical education) for greater consistency and objectivity in social work assessment, but they also conclude that student reflections on simulated interviews are important for establishing meta-competence to apply in new situations.

Empirical research on skills development is challenging in this context, while also essentially limited by ethical, pragmatic, and resource implications. Consistency and reliability for generalizability is constrained by levels of participation/sample size and representativeness, the degree of independence, and variability in definition/measures of outcome (Carpenter, 2005; Carpenter and Burgess, 2010; Koprowska, 2010; Lefevre, 2010). Trevithick et al. (2004) and Dinham (2006) drew attention to inconsistent terminology for skills ( $c f$. Evans, 2013) and definitions of effectiveness. Comparisons between diverse approaches are even harder. The importance of evidencing development of skills, changes in professional behaviour and transferability to practice remains.

\section{Use of role-play/video in skills development}

Effective learning activities to support social work communication skills/microskills teaching have long been established using role-play and groupwork, involving simulated practice interviews and feedback. Moss's study (2000), for example, of large-group peer role-play techniques noted Diploma of Social Work (DipSW/undergraduate) students' enthusiasm for role-play for linking theory to practice-related work in academic settings, but concluded that it needed to have interactive consistency for greatest impact. Video recording, video analysis, and involving service users and carers have extended this approach (see for example, Moss et al., 2007) but, as noted in other professions, using these for summative assessment of communication skills can be problematic and complex for maintaining professional 
relevance (Cartney, 2006). Nevertheless, Moss et al.'s study, using skills laboratories with service users and carers as actors and for feedback, found that these could be more effective for practicing 'real' skills and being able to change behaviours in response to feedback.

Cartney (2006) evaluated the introduction of a video assessment before placement in a single-centre case study where video recording, self/tutor/peer review and feedback were already used for formative feedback; this was supplemented by a written reflective self-evaluation based on the viewed interview. Cartney compared questionnaire responses from 25 of $32 \mathrm{DipSW}$ and 25 of 33 degree students. The students valued the contribution of video to both teaching and assessment but this was not linked to their assessment outcomes, and differences between students groups were unreported. Students also identified issues of 'scariness', performance anxiety and artificiality, despite valuing self-reflection and watching back (using technology) for improving their self-awareness and ability to change.

Bolger (2014) explored the development of communication skills and associated skills of reflection and self-assessment prior to placement in a small evaluation study in Scotland. Her study combined use of self, peer and educator feedback, role-play groupwork, and video-modelling and playback. Bolger found no statistical difference between pre- and post-test self-efficacy questionnaires on communication skills and independently assessed video interviews, but did find that participants considered most of their skills improved as a result of video-modelling, in particular, their reflective practice and their self-belief in competence. While the study benefited from 'real world' scenarios and a focus on context for the interview, limitations were acknowledged in its small scale $(n=11)$ and non-matching samples. Issues arising for these students were: anxiety on being observed, value of self-observation (body language), risk of 
artificiality, under/over-estimate of ability, and the importance of a safe/managed learning environment.

\section{Learning from Feedback}

Alongside acquisition of skills, the processes of learning for skills development are important; how a safe learning environment is created, in a workplace or simulated university-based environment, with/without skills laboratories, and using feedback (formative and summative), has particular relevance for professional courses.

Evans' systematic review (2013) of more than 6000 articles on feedback in higher education found little experimental evidence and was unable to draw specific conclusions on any consistent framework. From the key studies reviewed, Crisp's (2007) study of undergraduate social work students' responsiveness to written assessment feedback concluded that feedback was not instrumental in improving grades. While the ability to learn and respond positively to feedback received is a professional self-development skill (TCSW, 2012b), giving feedback can be more effective for educational learning and improving performance for the giver than receiver (Kim, 2009). Elsewhere, Heron, McGoldrick and Wilson (2015), researching written feedback in social work placements, identified different dimensions affecting responses to feedback - emotional and personal aspects, and the importance to students of relationships with feedback-givers.

A wide range of learning support arrangements and ground rules for structuring feedback have been used, but evidence of impact is harder to establish. Pendleton $e t$ al.'s 'rules' (Pendleton, Schofield and Tate, 1984) provide one established model of feedback, regularly used in social work and elsewhere (e.g., teaching medical consultation). These rules include a clear format for how feedback is requested, given and received by learner and observer to maximize consistency and give more control 
over feedback/discussion, enabling learners to assess their own performance safely. Bolger's (2014) study applied these 'rules' throughout preparation, filming and feedback phases of self-evaluation, group work and use of video.

In relation to the use of video feedback, Fukkink, Trienekens and Kramer (2011) provided a meta-analysis of thirty-three studies 1973-2009 (following up Fuller and Manning's prior review). Their meta-analysis investigated the effect of video play/feed-back on the interaction skills of a range of professionals, and found overall this was statistically significant. While feedback generally was more effective than practice alone, particularly at early stages of training, video playback offered intrinsically different opportunities for seeing oneself remotely and repeatedly. Fukkink et al. also noted the challenge of proving effectiveness and conflicting studies on comparative progress of undergraduates/postgraduates.

Nestel, Bello and Kneebone (2013), drawing on educational research/teaching of clinical procedural skills for medical students, summarised the value of simulation in skills laboratories for overcoming fragmentation of skills into isolated components and reducing artificiality of learning situations. Self-observation through video playback, allowed learners "to see how they performed rather than how they thought they performed" (Fanning and Gaba, cited in Nestel, et al., p. 143), promoting error detection skills and self-regulated learning (Zimmerman, cited in Nestel, et al., p. 144). Nestel et al. (2013) advocated using a range of multi-source independent feedback offering different 'expertise' — peers, academic staff, practitioners/practice educators, and service users and carers, and multi-method feedback (e.g., written, verbal, reflective, video playback, and self-assessment questions).

In summary, important characteristics of effective feedback are: controlled, specific, structured and positive/constructive, enhancing change (in desired and 
undesired behaviours), providing opportunities for positive self-modelling and empowerment, and linked with teaching /development/modelling to inform and change understanding and behaviours (Fukkink et al., 2011). While a wide range of feedback sources is now established in learning models, there are still questions about the comparative effectiveness of feedback/self-evaluation, including video feedback, on social work skills prior to placement.

\section{Methodology}

Aim: This qualitative study focuses on factors identified by social work students on an undergraduate (UG) and postgraduate (PG) programme as significant in helping or hindering their skills development on a common module, building on existing module evaluation and student self-assessment systems. More details of methodology and questionnaire in this study are provided elsewhere (Tompsett et al., 2016, in review)

\section{Context for the Research}

The module is designed to enable students to develop core skills in: communication and interviewing, initial assessment and writing, and reflection. It contributes to students' overall assessment at the RDP level. Teaching and assessment for this professional foundation module is provided at undergraduate academic level to all UG and PG students at this university, with all other modules differentiated by programme level. Students have to pass four separately assessed elements: simulated Interview with a service user/carer, written Report and reflective Self-evaluation of the assessed interview, and Portfolio of skills workbook.

Students were taught in six workshop groups (four UG, two PG) over the academic year 2013-14. Role-plays, based on scenarios developed with actual service users and carers, were practised in peer triads with interviewer/'service user'/ observer 
roles using a new dedicated practice learning suite/skills laboratory. Common theoretical and contextual input, teaching on professional values and behaviour, and modelling of skill techniques took place within workshops, with additional support provided online.

Role-plays of the practice/mock and assessed interview were recorded as video and made available to individual students for review online, within workshops and individually. Peers and tutors provided feedback on role-plays, based on Pendleton et al.'s 'rules' (1984), with additional formative feedback provided by service users/carers and practice educators.

Ninety-four students started the module, with 88 completing to assessment (56 UG, 32 PG), excluding deferrals and withdrawals during the year, and 83 (94\%) passing overall.

The research team contributing to research design and progress included all academic staff teaching on the combined module team, an independent researcher and an analyst, all associated with the university in the study.

\section{Questionnaires}

The data was taken from three identical self-assessment questionnaires issued to students at the beginning (T1), midpoint (T2), and end of the module teaching schedule (T3) and students were given ten minutes during workshop sessions to complete each one.

Each questionnaire contained two sections, with a detachable top-sheet, on which it was made clear the questionnaire formed part of students' self-assessment on the module and students asked to provide ID numbers (for correlation between stages of the research). Two additional questions, on the first questionnaire top-sheet, asked for 
students' workshop group and the number of years of relevant work experience already undertaken.

In the first section, students were asked to assess their current ability, using a Likert scale (1-5), to perform each of 29 skills/microskills 'as if in practice', based on the module curriculum (see Henderson and Mathew Byrne, 2016, for teaching approach); microskills include, e.g., use of minimum encouragers, open/closed/probing questions, paraphrasing, etc. Responses to this section at T3 were used to establish the self-efficacy scale (see Introduction).

In the second section, students were asked to respond to two questions:

Q1: Please describe the aspect of the module so far that has helped you develop your skills the most.

Q2: Please describe the aspect of the module that has been the least useful in developing your skills so far.

This paper discusses the qualitative analysis of responses to Q1 and Q2 across all three stages.

\section{Participants, Sampling Procedures and Ethics}

The voluntary questionnaires were integral to the module and all students had completed course participatory consent forms, which included this module. Separate ethical clearance was not required by the Faculty, as the researchers assisted the module team in the construction of the questionnaire, but remained independent of assessment and student contact, and used only anonymised data for the analysis. Students on the module at $\mathrm{T} 1$ were considered potential subjects, and were invited to complete questionnaires, but could choose to complete or not, and/or omit their identifying student number. All three questionnaires included a statement that neither the module 
team nor other academic staff would have access to information given and it could not be used in their formal assessment, and students were informed that their data, if provided, would contribute to research and be used for module evaluation and development. Students who missed the workshop in which a questionnaire was presented were allowed to complete it in their own time, and all students were presented at the end of the module with a written research feedback report including their comments.

This analysis is based on responses to 252 questionnaires from 88 students who provided their student number on questionnaires (see Table 1).

[Table 1 about here]

\section{Open Coding and Units of Analysis}

The analysis is based on Grounded Theory (Glaser and Strauss 1967).

Open codes were hand-written onto anonymized scripts during first reading. Responses varied in length from single words to longer explanations that were subdivided into separate statements linguistically, ensuring codes remained consistently linked with distinct parts of a response. The full set of statements $(n=633)$ was transcribed into FileMakerPro ${ }^{\mathrm{TM}}$ based on an agreed reading of the text (with minor grammatical changes to facilitate data searching). The data was then exported and autocoded in NVivo ${ }^{\mathrm{TM}}$.

On completion, 60 codes were developed (see below). The ratio of statements between programmes matched the ratio of students (UG 60\%, PG 40\%).

\section{Analysis of Short Statements}

Approximately one-third of the statements were short and generated five, non-specific codes: 'universally positive', 'none, n/a, etc.', 'blank', 'too early to say' and 'out of 
context'. No code was needed for a general negative response. Table 2 summarises the use of these codes by programme level and stage.

[Table 2 about here]

The level of approval evident in positive statements in this analysis remains consistently high across all stages, though UG statements are more strongly expressed:

I can't really say any part of this module has not been helpful. I think it is a great module that puts theory into practice. [S009,T3,Q2] UG

All aspects of this module have been educational and beneficial to my development. [S064,T3,Q2] PG

\section{Analysis of Specific Responses}

This level of analysis focuses on the 419 statements that included specific details. There were considerably more for Q1 (318) than for Q2 (94), with seven further comments added by students (see Table 3 ).

[Table 3 about here]

Four code categories were generated for: 'key student learning/skills', 'high impact learning activities', 'learning support/feedback' and 'memorable/significant sessions/topics'. Two other categories were introduced for 'module delivery issues' and 'other issues affecting learning'. The 'learning support/feedback' category included self-observation, observation of others, and group-work and three kinds of feedback (from peers, tutors, and 'externals'- practice educators, service users and carers).

\section{Skills identified by students}

Students identified in their own words seven module-specific skills developed during the module, and five additional self-development abilities, referred to more frequently though only partially taught (see Tables $4 \mathrm{a}, \mathrm{b}$ ). Their focus at $\mathrm{T} 1$ was on communication/interviewing skills, but at $\mathrm{T} 2$ and $\mathrm{T} 3$, self-assessment and self- 
awareness were increasingly frequently mentioned. Undergraduates made more generally positive comments about the impact of the module on skills development, but there was no other noticeable difference, proportionately, between UGs/PGs relating to specific skills.

[Tables $4 \mathrm{a}, \mathrm{b}$ about here]

\section{Q1: Factors helping skills development most?}

In response to Q1, 'practice interviews', 'use of technology' and 'self-observation' occurred with most frequency (see Table 5), particularly at T2 and T3.

[Table 5 about here]

These three are clearly inter-related. 'Practice interviews', including workshop interviews in triads and both mock and assessed interviews (as opposed to 'role-plays' an additional 23 statements), were directly associated with 'use of technology' comments that focused mainly on the availability of video and playback facilities. This enabled 'self-observation' - opportunities for students to identify communication/interviewing errors ("see mistakes", "bad habits", "unhelpful body language", "what needs correcting"), critically reflect on performance ("breaking down" perceptions of oneself), "connect practice with theory", and "be more self-aware when doing it again".

Being able to watch myself on the screen helped me to understand how I am experienced by a service user [S067,T2 Q1] PG

Watching myself on video has been very helpful in identifying any nervous tendencies. However, it has given me more confidence as I realised that a situation where I thought I had done poorly, was actually better than I thought. ... [S044,T3,Q1] UG

Feedback in general was rated important to student learning (33 statements) and 'working in groups' rated highest of other feedback/learning support sources, 
particularly at $\mathrm{T} 1$ for stimulating and complementing self-reflection, by playing "different roles", "learning from/watching/practicing with others", "telling others" how you think you performed and "explaining actions" (16 statements).

It is very helpful to get peer feedback on my interview techniques and to be able to discuss ways of improving but also to reflect on reasons for my weakness [S079,T1,Q1]

Formative feedback from tutors was described as authoritative, providing comments on techniques and helpful tools/models, while feedback and inputs from practice educators, and service users and carers appeared "real", supporting the value of simulation, despite the potential authenticity question noted later.

Some of the most beneficial sessions were when outside people came in, e.g., the ‘angry' service user ... [S079,T3,Q1].

\section{Q2: Factors least useful for skills development?}

Statements in response to Q2 showed marked variation in emotional response. Activities with most emotional impact generated conflicting responses between students and differentially affected confidence. A simulated de-escalation role-play session with 'aggressive' service users aroused mixed reactions from both UGs and PGs (9 statements):

...- at the time it completely knocked my confidence and has stuck with me to this day $[\mathrm{S} 091, \mathrm{~T} 3, \mathrm{Q} 2]$.

A range of emotions were also associated with the use of video (anxiety, distress, exposure, embarrassment - 16 statements), e.g., "having video clips replayed in front of workshop groups", or feeling deskilled in role-plays. Some offset this with comments valuing support from peers and tutors, or describing 'hard' learning, iterating the 
importance of feeling safe in the learning environment. Only one student found reintegrating component communication skills challenging.

I was very scared about the video recording sessions however, this experience has enhanced my confidence and interview skills placing me at where I am now compared to before [S038,T3,Q1]

Several statements recognizing difficulties in learning attributed this to students' own issues, what they regarded as (personally) difficult and 'daunting', an aspect they knew needed development, or a mis-assessment on their part of their skill level. Six students commented at T3 that they realized they had in earlier questionnaires overestimated their level of skill. The statement below exemplifies the challenge and possible rewards involved in reviewing their performance:

There are times I have had to be more reflective in a changing setting. Very good learning journey [S070, T2, Q2]

Remaining factors identified as least useful for skills development varied through the study. Initially, these focused on transient effects such as settling-in and/or group dynamics (T1, 11 statements) or contradictory issues noted as positive by other students, e.g., whether simulated interviews offered authentic or flawed preparation for real/realistic practice (six positive statements, seven negative). Later statements identified minor module delivery aspects or perceived gaps in content/preparation for practice, e.g., use of Powerpoint ${ }^{\mathrm{TM}}$, wanting more time with service users, or on communication with children (T3, 29 statements).

\section{Third level of analysis:}

From the preceding analysis, the close interplay between technology and learning and indications of differences between UG and PG students became clear; this was 
confirmed by searching for codes reflecting a marked difference between programme level (see Table 6).

[Table 6 about here]

Longer statements/“explanations’ that characterize learning as a process were particularly interesting, as in the undergraduate statement below.

Recordings of simulated interviews have been very useful in making me aware of areas I need to develop. For example: before I started RDP my communication skills were very poor, however I have practised more and improved on my communication with others. [S034,T2,Q1]

The use of linguistic features in the initial coding suggested that a systemic function grammar (Thompson, 2007) could be used as a grounded approach to building an underlying axial model for learning processes on the module ( $c f$. theoretical sensitivity, Strauss and Corbin, 1990, p. 42) and exploring any differences between students by programme; the remainder of the analysis is based on this (cf. Ogborn and Bliss, 1977). Systemic function grammars (SFGs) distinguish three interrelated functions of language: the ideational, the interpersonal and the textual. The following analysis focuses only on the ideational function, used to describe and reason about the 'world'. Figures 1a, 1b, illustrate the UG statement above, using the underlying grammar generated for the set of statements referring to learning support/feedback/selfobservation, that reflected some aspect of learning as a process (84 statements). Thompson (2007, p. 36ff) provides a useful description of the notation used.

[Figures 1a, b about here]

This approach allows the characteristic pattern of explanations by students on each programme to be contrasted, by over-laying corresponding representations for each 
statement (see Figures 2a, b, c). In Figures 2a, 2b, the length of bars and width of links represent relative frequency of associations within the set.

Across both programmes, the importance of practice interviews remains clear, but the sequence of associations between practice interviews, recording of interviews, self-observation and the ability to self-assess and develop self-awareness is more strongly characteristic for UGs than PGs. It is also clear that UG students show greater consistency in their comments than PG students, despite the larger UG student numbers.

[Figures 2a, b, c about here]

For PGs, a wider range of feedback is valued with a corresponding reduced emphasis on self-observation. Exploring this within the set of statements reveals a greater focus on their assessment of quality of feedback. Feedback from tutors is highly valued but comments from peers are considered to be acritical or over-familiar ("too calm and nice"), leading to requests to interview students from other workshop groups, for example. PGs also identified a wider range of learning activities, other than the practice interview, for promoting confidence, and PGs were more inclined to identify authenticity issues, citing limitations in representing complexity, for example.

UGs rated groupwork particularly highly. The stronger emphasis in UG statements on practice interviews also prompted further analysis: UGs focused more on developing specific skills/techniques in workshop triads (UG 60: PG 31), whereas PGs focused more on the mock and assessed interviews (UG 9: PG 14). This mirrors differences emerging in learning styles and approaches (see Table 6), between UG interactive learning/reflection-focused on self and improving practice, and PG learning from reflective writing sessions (models, theories and tools) — focused on analysing practice. 
The reflective tools ... supplied and suggestion to do a reflective diary. I've extended it to keep a weekly log of the York model, ... which helped me deconstruct my own capacity as a student, my weaknesses and strengths and identify how I can build resilience (S045,T3,Q1) PG

The best part of the module is watching myself back on the recordings and receiving constructive criticism from my peers and practice teachers. ... This has highlighted what I am doing well and what I need to improve on. This was a brilliant learning style [S095,T3,Q1] UG

\section{Discussion of Findings}

The findings, based on what students valued for their core skills development and identified most frequently in questionnaire responses, confirm that for all students video recording of practice interviews was instrumental as a self-feedback process for assessing performance, especially in communication skills. It became increasingly significant over the stages, and more significant than any other forms of direct feedback. This study reinforces the usefulness of video to support modelling of desired behaviour (cf. Cartney, 2006; Bolger, 2014) and the value of video feedback for self-regulatory aspects of learning (Fukkink et al., 2011, Nestel et al., 2013).

The most clearly differentiated findings were in undergraduate and postgraduate responses to feedback from others on communication skills. Undergraduates particularly focused on the value of self-observation, but also the experiential, shared learning environment of being in a group. Privacy of self-observation offered by video playback, and the safety in numbers of groupwork have together provided the 'safe' learning environment, important to undergraduates at their stage of study ( $c f$. Moss's (2000) and Bolger's (2014) studies with undergraduates). Postgraduates demonstrated, in their descriptions and reasoning, different learner expectations and preferences (compared to undergraduates) on range and quality of feedback, although they shared a common, if lesser, appreciation of self-observation. Postgraduates valued tutor feedback 
and the mock and assessed interview experience more than peer feedback, preferring feedback that was more finely tuned, credible and outcome-focused; this may be associated with understanding the value of feedback after previous academic success (cf. Crisp, 2007, with undergraduates). Unlike Heron et al.'s study (2015), authority, expertise and independence of feedback were also more important to postgraduates in this study than having a good relationship with the giver of feedback.

Only a small number of students referred to the issue of authenticity, when using simulated experiences as preparation for practice, unlike Cartney's (2006) and Bolger's (2014) studies, and this was mainly linked (for postgraduates) to peer feedback issues; similarly, only one student referred to the challenge of reintegrating component communication skills ( $c f$. Crisp and Lister, 2002; Eadie and Lymbery, 2007; Bogo et al., 2013). Factors such as 'real' feedback and the involvement of service users and practitioners appear to have helped overcome any potential artificiality of the learning situation and provide a context for learning (cf. Lefevre et al., 2008). It will be interesting to follow up in placement with the next cohort whether students can make the transfer of skills/reflection/learning from feedback to practice contexts.

Both sets of students identified the emotional impact of learning on them, and issues of anxiety associated with feeling exposed and out of their comfort zone ( $c f$. Cartney, 2006; Bolger, 2014). As 'professional' learners at the first stage of professional training, it is not surprizing that students mastering skills/microskills particularly in communication/interviewing felt de- or un-skilled. Many described having to learn/relearn/unlearn strategies and techniques, as previously held beliefs/experiences about their communication approaches were challenged. The range of emotions experienced reflects the range they may experience in practice, for example, distress and/or fear when dealing with aggression and feeling incompetent interviewing in 
challenging situations ( $c f$. Parker, 2006; Forrester et al., 2008), but also the sense of achievement possible, when initial qualms are overcome and performance/relationships improve (Ruch et al., 2010).

The RDP threshold level requires "learning from feedback" and achievement of core skills for eligibility to proceed to placement. Students discussed becoming more aware of helpful/not helpful behaviours, and more able to assess and improve on strengths/weaknesses, and it was self-development abilities that were more frequently identified as skills developed, despite module-specific skills such as communication/interviewing being a primary focus of teaching and video feedback ( $c f$. Fukkink et al., 2011). Self-assessment and self-awareness, the two most mentioned, were clearly represented by students as the means to improve all their skills and their confidence ( $c f$. Maxwell et al, 2016). These also reflect the first level of benefit from critical reflection (Fook and Gardner, 2007), providing a foundation before core skills are tested and challenged in practice/ workplace/placement contexts (Collins and Bogo, 1986, Trevithick, 2012). Such awareness, emotional intelligence and meta-competence (Bogo et al., 2013) matches with the professional self-protection needed for dealing with emotional demands and new practice situations (Munro, 2011; Croisdale-Appleby 2014), and as identified by students/practitioners on placement and in practice (Parker, 2006; Forrester et al., 2008)

Student engagement and participation was high for undergraduates and postgraduates with nearly $100 \%$ participation at some stage (contrasting with Koprowska, 2010). Interestingly, students' generally positive statements on the module are juxtaposed, in the smaller number of more critical comments, with a focus on individual learning challenges- reflecting primarily their own perceived learning journey. 


\section{Strengths and limitations}

This study investigating perceptions of learning processes, particularly in relation to impact of video technology, has contributed to research on learning of communication and other core skills and at RDP level, building on Bolger's (2014) study, but with a larger sample ( $c f$. Koprowska, 2010) and using students' unprompted comments on (and perceptions of) feedback. The study has also provided a comparison between undergraduate and postgraduate learning experiences to complement the quantitative study (reported elsewhere). The use of a systemic functional grammar with a qualitative grounded theory approach has produced a systematic representation of integrated learning and feedback, more revealing than a co-occurrence analysis.

Opportunities to contribute to feedback for other students in this study (cf. Kim, 2009), and quality, breadth and means of receiving feedback for themselves have contributed to a positive learning environment, evident in students' overall positive evaluation of the learning experience.

Feedback to the course team has enabled change in module delivery: e.g., addressing student anxiety on being recorded, more 'feed forward' from tutors, and reviewing both actor preparation and student debriefing for the simulated de-escalation session.

Four limitations of the study are identified. It is, as yet, restricted to one year's cohorts in one university; planned replication, enlarging the sample to include the following year's cohorts, will strengthen the analysis. Separation of researchers/teaching team contributed to independence of the study, but may risk misinterpretation of students' brief responses to open questions or affect codes selected. In addition, it has not been possible to test the axial model as expected by Grounded Theory, although this could raise issues of consistency with SFGs. 


\section{Conclusions}

This study, focusing on student perceptions of what was most helpful and least useful for core skill development, found overwhelmingly positive views of the learning experience preparing them for the RDP threshold assessment. It highlighted the value in communication skills of self-observation and self-feedback for all the students afforded by video recording of practice interviews. This enabled them, as developing learner professionals, also to be self-aware and reflect critically on their learning and practice, as they refined their communication and interviewing techniques. There was no difference between undergraduate and postgraduate students in their appreciation of the wide range of feedback mechanisms for a constructive safe learning environment, or in the quantitative outcomes in assessment for the two groups (Tompsett et al., 2016, in review). However, there were differences in degree of value attributed to selfobservation and in learning preferences - postgraduates valuing multi-source feedback, particularly from authoritative, independent and credible sources, while undergraduates valued peer support in groupwork. These differences may be important for tailoring learning or making adjustments to module delivery, but they do not necessarily justify different expectations in relation to assessment outcome at RDP level, based on programme level. Involvement of service users and carers and practitioners/practice educators, and facilities offered by the practice learning suite/skills laboratory have been critical to supporting students on a learning journey relevant to realistic, if not yet real, practice.

Acknowledgements: The research project team would like to thank all those students, academic staff, technicians, practice educators and service users and carers who participated in the module and contributed data for this evaluation. We would also like to thank participants and the School and Faculty Research Conference workshops for their views, which contributed to the learning from this project. 


\section{References}

Adams, R., Dominelli, L., \& Payne, M. (Eds.) (2002). Critical practice in social work (pp. 1-16). Basingstoke: Palgrave

Bogo, M., Regehr, C., Woodford, M., Hughes, J., Power, R., \& Regehr, G. (2006). Beyond competencies: Field instructors' descriptions of student performance. Journal of Social Work Education, 42, 579-593.

Bogo, M., Katz, E., Regehr, C., Logie, C., Mylopoulos, M., \& Tufford, L. (2013). Toward understanding meta-competence: An analysis of students' reflection on their simulated interviews. Social Work Education, 32, 259-273.

Bolger, J. (2014). Video self-modelling and its impact on the development of communication skills within social work education. Journal of Social Work, 14, 196-212.

Bruce, L. (2013). Reflective practice for social workers: A handbook for developing professional confidence. Maidenhead: Open University Press.

Carpenter, J. (2005). Evaluating outcomes in social work education. Dundee and London: Scottish Institute for Excellence in Social Work Education and Social Care Institute for Excellence.

Carpenter, J., \& Burgess, H. (2010). The OSWE Project: collaborating to develop the evaluation of outcomes of social work education, in J. Carpenter \& H. Burgess (Eds.) (2010) (pp. 7-15).

Carpenter, J. and Burgess, H. (Eds.) (2010) Monograph 2: The Outcomes of Social Work Education: developing evaluation methods, Retrieved from www.swap.ac.uk/docs/monograph2_oswe.pdf

Cartney, P. (2006). Using video interviewing in the assessment of social work communication skills. British Journal of Social Work, 36, 827-844.

Collins, D., \& Bogo, M. (1986). Competency-based field instruction: bridging the gap between laboratory and field learning. Clinical Supervisor, 4, 39-52.

Council on Social Work Education (CSWE). (2015). Educational Policy and Accreditation Standards (2015). Retrieved from www.cswe.org/Accreditation/83509/81660.aspx

Crisp, B. (2007). Is it worth the effort? How feedback influences subsequent submission of assessable work. Assessment and Evaluation in Higher Education, 32, 571581. 
Crisp, B., \& Lister, P. (2002). Assessment methods in social work education: A review of the literature. Social Work Education, 21, 259-269.

Croisdale-Appleby, D. (2014). Re-visioning social work education, an independent review. Retrieved from www.gov.uk/government/publications/social-workeducation-review

Department for Education (DfE). (2014a). Knowledge and Skills for child and family work (Consultation outcome). Retrieved from www.gov.uk/government/consultations/knowledge-and-skills-for-child-andfamily-social-work

Department for Education (DfE). (2014b). Nicky Morgan announces children's social work reforms (Transcription of conference presentation). Retrieved from www.gov.uk/government/ speeches/nicky-morgan-announces-childrens-socialwork-reforms

Department for Education (DfE). (2016). Children's Social Work Reform Inquiry launched. Retrieved from www.parliament.uk/business/committees/committeesa-z/commons-select/education-committee/news-parliament-2015/childrensocial-work-reform-launch-15-16/

Department of Health (DH). (2014). Knowledge and skills statement for social workers in adult services (Consultation outcome). Retrieved from Www.gov.uk/government/consultations/adult-social-work-knowledge-and-skills

Dinham, A. (2006). A review of practice of teaching and learning of communication skills in social work education in England. Social Work Education, 25, 838-850.

Eadie, T., \& Lymbery, M. (2007). Promoting creative practice through social work education. Social Work Education, 26(7), 670-683.

Eraut, M. (1994). Developing professional knowledge and competence. London: Falmer.

Evans, C. (2013). Making sense of assessment feedback in Higher Education. Review of Educational Research, 83, 70-120.

Fook, J., and Gardner, F. (2007). Practising critical reflection. Maidenhead: Open University Press.

Forrester, D., McCambridge, J., Waissbein, C., \& Rollnick, S. (2008). How do child and family social workers talk to parents about child welfare concerns? Child Abuse Review, 17, 23-35. 
Fukkink, R.G., Trienekens, N., \& Kramer, L. (2011). Video feedback in education and training: Putting learning in the picture. Educational Psychology Review, 23, 4563.

Glaser, B. G., \& Strauss, A. L. (1967). The discovery of grounded theory: strategies for qualitative research. London: Weidenfeld and Nicholson.

Health and Care Professions Council (2012). Standards of proficiency for social workers in England. Retrieved from www.hcpcuk.org/assets/documents/ 10003B08Standardsofproficiency-SocialworkersinEngland.pdf

Henderson, K. \& Mathew Byrne, J. (2016). Developing communication and interviewing skills. In K. Davies \& R. Jones (Eds.) Skills for Social Work Practice (pp. 1-22). London: Palgrave.

Heron, G., McGoldrick, R., \& Wilson, R. (2015). Exploring the influence of feedback on student social workers' understanding of childcare and protection. British Journal of Social Work, 45, 2317-2334.

Ivey, A. (1982). Intentional interviewing and counseling: The microskills approach. Retrieved from www.donpugh.com/PsychInterests/counselling/the\%20microskills\%approach.pd $\mathrm{f}$

Keville, H. (2012). Assessing practice using the professional capabilities framework. Retrieved from https://www.basw.co.uk/resources/tcsw/Assessing\%20practice\%20using\%20the \%20PCF\%20guidance.pdf

Kim, M. (2009). The impact of an elaborated assessee's role in peer assessment. Assessment and Evaluation in Higher Education, 34, 105-114.

Koprowska, J. (2010). Are student social workers' communication skills improved by university-based learning? in J. Carpenter \& H. Burgess (Eds.) (2010) (pp. 7387).

Laidlaw, A., \& Hart, J. (2011). Communication skills: An essential component of medical curricula. Part I: assessment of clinical communication (AMEE guide no. 511). Medical Teacher, 33(1), 68.

Lefevre, M., Tanner, K. \& Luckock, B. (2008). Developing social work students' communication skills with children and young people: a model for the qualifying level curriculum. Child and Family Social Work, 13(2), 166-176. 
Lefevre, M. (2010). Evaluating the teaching and learning of communication skills with children and young people, in J. Carpenter \& H. Burgess (Eds.) (2010) (pp. 96110).

Luckock, B., Lefevre, M., Orr, D., Jones, M., Marchant, R. \& Tanner, K. (2006). SCIE Knowledge Review 12: Teaching, learning and assessing communication skills with children and young people in social work education. Retrieved from http://www.scie.org.uk/publications/knowledgereviews/kr12.asp

Maxwell, N., Scourfield, J., Le Zhang, M., de Villiers, T., Pithouse, A. and Tayyaba, S. (2016). Independent Evaluation of the Frontline pilot: Research report. Retrieved from https://www.gov.uk/government/publications

Moriarty, J., Baginsky, M. \& Manthorpe, J. (2015). Literature review of roles and issues within the social work profession in England. Retrieved from https://www.socialwelfare.bl.uk/subject-areas/services-activity/social-workcare- services/ socialcareworkforceresearchunit/ 174392moriarty-et-al-2015PSA.pdf

Moss, B. (2000). The use of large-group role-play techniques in social work education. Social Work Education, 19, 471-483.

Moss, B., Dunkerly, M., Price, B., Sullivan, W., Reynolds, M., \& Yates, B. (2007). Skills laboratories and the new social work degree: one small step towards best practice? Service Users' and Carers' Perspectives. Social Work Education, 26, 708-722.

Munro, E. (2011). The Munro Review of Child Protection: A child-centred system.. Retrieved from https://www.gov.uk/government/publications/ munro-review-ofchild-protection-final-report-a-child-centred-system

Narey, M. (2014). Making the education of social workers consistently effective. Retrieved from https://www.gov.uk/government/publications /making-the-education-of-social-workers-consistently-effective.

Nestel, D., Bello, F., \& Kneebone, R. (2013). Feedback in clinical procedural skills simulations. In D. Boud and E. Molloy (Eds.), Feedback in Higher Education: Understanding it and doing it (pp. 140-157). Abingdon: Routledge.

Ogborn, J. \& Bliss, J. (1977). Students' reactions to undergraduate science. London: Heinemann Educational.

Parker, J. (2006). Developing perceptions of competence during practice learning. British Journal of Social Work, 36, 1017-1036. 
Pendleton, D., Schofield, T., \& Tate, P. (1984). The consultation: An approach to learning and teaching. Oxford: Oxford University Press.

Ruch, G., Turney, D., \& Ward, A. (2010). Relationship-based social work. London: Jessica Kingsley.

Sheppard, M. \& Charles, M. (2014). Critical thinking and interpersonal dispositions in those commencing social work training. British Journal of Social Work, 44, 2057-2066.

Sheppard, M. \& Charles, M. (2015). Head and heart: an examination of the relationship between the intellectual and interpersonal in social work. British Journal of Social Work, 45(6), 1837-1854.

Social Work Reform Board. (2010). Building a safe and confident future: Full detailed proposals from the Social Work Reform Board. Retrieved from https://www.gov.uk/government/collections/social-work-reform-board

Strauss A. L., \& Corbin, J. (1990). Basics of qualitative research: grounded theory procedures and techniques. London: Sage.

The College of Social Work (TCSW) (2012a). Professional Capabilities Framework. Retrieved from www.basw.co.uk/upload/_basw_122248-9.pdf

The College of Social Work (TCSW) (2012b). Readiness for practice. Retrieved from cdn.basw.co.uk/upload/basw_32426-7.pdf

Thompson, G. (2007). Introducing Functional Grammar. Abingdon: Routledge.

Tompsett, H., Henderson, K., Gaskell Mew, E., Mathew Byrne, J. \& Tompsett, C. (2016). Self-efficacy and outcomes: validating a measure comparing social work students' perceived and assessed ability in core pre-placement skills. British Journal of Social Work (in review).

Trevithick, P., Richards, S., Ruch, G., \& Moss, B. (2004). Knowledge Review 6: Teaching and learning communication skills in social work education. Retrieved from http://www.scie.org.uk/publications/knowledgereviews/kr06.asp

Trevithick, P. (2012). Social Work Skills and Knowledge: A Practice Handbook. Buckingham: Open University Press. 
Table 1. Questionnaires returned by stages and programme level $(n=94)$.

\begin{tabular}{lcccc}
\hline Programme & Students & T1 & T2 & T3 \\
\hline UG & 56 & 52 & 54 & 52 \\
PG & 32 & 32 & 31 & 31 \\
Unidentifiable & 6 & 6 & 0 & 0 \\
All & 94 & 90 & 85 & 83 \\
\hline
\end{tabular}

Table 2. Statements by stages and programme level $\left(n=197^{\dagger}\right)$.

\begin{tabular}{lccccccc}
\hline & \multicolumn{3}{c}{ T1 } & \multicolumn{3}{c}{ T2 } & \multicolumn{2}{c}{ T3 } & \\
\cline { 2 - 7 } Coded response (Questions) & UG & PG & UG & PG & UG & PG & Total \\
\hline $\begin{array}{l}\text { Universally +ve statement } \\
\text { (Q1, Q2) }\end{array}$ & 12 & 4 & 14 & 4 & 25 & 8 & 68 \\
$\begin{array}{l}\text { None, n/a, no comment } \\
\text { (Q2 only) }\end{array}$ & 32 & 7 & 16 & 5 & 11 & 6 & 77 \\
Blank response (Q1) & 3 & 2 & 0 & 1 & 1 & 0 & 7 \\
$\begin{array}{l}\text { Blank response (Q2) } \\
\text { Overall total }\end{array}$ & 5 & 7 & 11 & 12 & 5 & 5 & 45 \\
\hline omitting four unidentifiable students and 13 coded 'too early to say'/‘out of context')
\end{tabular}

Table 3. Statements coded for specific content by stages $(n=412)$.

\begin{tabular}{lcccc}
\hline Statements in responses to: & T1 & T2 & T3 & Total \\
\hline Q1 & 88 & 106 & 124 & 318 \\
Q2 & 17 & 25 & 45 & 94 \\
\hline
\end{tabular}


Table 4a. Module-specific skills by programme level (46 statements)

\begin{tabular}{lcc}
\hline Skills & UG & PG \\
\hline communication/interviewing skills & 16 & 8 \\
reflective/reflection skills & 7 & 3 \\
$\begin{array}{l}\text { others: writing skills; structuring contact skills; rapport } \\
\quad \text { building skills; understanding service user perspectives } \\
\quad \begin{array}{l}\text { and empathy; maintaining and awareness of values, } \\
\text { attitudes, beliefs }\end{array}\end{array}$ & 6 & 6 \\
\hline
\end{tabular}

Table 4b. Self-development abilities by programme level (124 statements)

\begin{tabular}{lcc}
\hline Abilities & UG & PG \\
\hline self-assessment (strengths, weaknesses, gaps) & 29 & 17 \\
self-awareness & 21 & 10 \\
self-confidence & 15 & 5 \\
$\begin{array}{l}\quad \text { recognizing emotional impact of experiences } \\
\quad \text { happiness/distress feelings) }\end{array}$ & 8 & 8 \\
ability to change & 6 & 5 \\
\hline
\end{tabular}

Table 5. Occurrence of specific codes by stages in response to Q1

\begin{tabular}{lcccc}
\hline Codes within categories & T1 & T2 & T3 & Total \\
\hline practice interviews & 25 & 43 & 46 & 113 \\
use of technology & 2 & 30 & 34 & 66 \\
self-observation & 1 & 24 & 29 & 54 \\
\hline
\end{tabular}


Table 6. Codes reflecting marked differences between UG and PG programme levels.

\begin{tabular}{|c|c|c|}
\hline \multirow[t]{2}{*}{ Difference: } & \multicolumn{2}{|c|}{ Code (UG statements, PG statements) } \\
\hline & More references by UGs & More references by PGs \\
\hline Major & $\begin{array}{l}\text { use of technology }(54,12) \\
\text { self-observation }(42,12)\end{array}$ & $\begin{array}{l}\text { authenticity (realistic v false) }(3,10) \\
\text { practice educator session }(0,5) \\
\text { interview structuring session }(0,5)\end{array}$ \\
\hline Noticeable & & $\begin{array}{l}\text { lecturing materials/delivery }(17,24) \\
\text { feedback from tutors }(3,9) \\
\text { activities promoting/hindering } \\
\text { confidence }(7,12)\end{array}$ \\
\hline Minor & doing reflection $(12,3)$ & $\begin{array}{l}\text { feedback from peers }(+/-)(6,10) \\
\text { role play/scenarios }(10,13) \\
\text { reflective writing session }(5,8)\end{array}$ \\
\hline
\end{tabular}

